\title{
INTRODUCTION: INFECTIOUS DISEASES FORUM
}

\section{TIMOTHY CAULFIELD*}

The 2003 SARS outbreak brought public health issues to the forefront of legal and scientific inquiry. It both highlighted the potential deficiencies of the existing disease control schemes and stimulated a national and international dialogue on the development of new public health policies.

In this Forum, the legal and social issues associated with control of infectious disease are explored at the level of provincial, national and international governance. Numerous themes flow through all the articles, including: the complex task of balancing individual rights, such as the right to consent to treatment, against the need to protect public health; the need to ensure that legal and health care responses are coordinated; and the necessity of building systems to ensure that all policy development and disease response activities be appropriately informed by the best available scientific information and ethics analysis.

Rosario Isasi and Thu Minh Nguyen's article discusses the policy challenges associated with the global governance of infectious disease. They do this through the lens of the World Health Organization, an entity that has played a foundational role in international public health policy. During the SARS outbreak, it became clear that a high degree of international co-operation is crucially important to the control and containment of disease, including the rapid sharing of accurate and standardized incident reporting. However, ensuring international cooperation remains a huge challenge, as it may be viewed as a threat to state sovereignty. Nevertheless, with the possibility of new pandemics on the horizon, such as avian flu, the development of a coherent international approach to disease control seems essential.

The article by Mireille Lacroix explores Quebec's unique public health system.' In addition, she reviews the key elements of public health ethics, including how it differs from traditional biomedical ethics (such as a focus on populations instead of on individual patients). Few, if any, jurisdictions have a formal process that allows for in-depth deliberations on relevant ethics issues. Lacroix explains Quebec's decision to include an ethics review committee as part of the overall public health framework. The Quebec system also incorporates a broader definition of "surveillance," such that it includes the collection of information about demographics, socio-economic status and lifestyle. The goal of the approach is to provide the information necessary to develop effective preventative strategies.

Finally, the article by Nola Ries provides an overview of the Canadian experience with SARS and the relevant legal mechanisms used to control the spread of disease. The focus of the article is on quarantine - one of the oldest and, in some respects, most severe public health tools. Ries notes the need to modernize the existing provincial and federal laws that relate to the process of quarantine. She also explores the potential legal issues associated with

Canada Research Chair in Health Law and Policy; Professor, Facully of Law and Faculty of Medicine; Research Director, Health Law Institute, University of Alberta.

Public Health Act, R.S.Q.. c. S-2.2. 
the use of quarantine. Given that it is a public health tool that can involve the forced confinement of individuals, quarantine orders clearly have the potential to implicate the Canadian Charter of Rights and Freedoms. ${ }^{2}$ Ries notes that, although Canadian courts have been relatively deferential to the needs of public health authorities (for example, the identification and reporting of infected individuals), future uses of the quarantine power may be more difficult to rationalize without clear evidence of need and effectiveness.

It is hoped that the articles in this Forum, which are the result of an ongoing research project funded by the Canadian Institutes of Health Research (CIHR), ${ }^{3}$ will help to inform policy development in Canada and stimulate further analysis into the complex issues associated with the control of infectious disease.

: Part I of the Constitution Act, 1982, being Schedule B to the Canada .fCt 1982 (U.K.), 1982, c. 11. "The Legal Foundalions for a National Disease Control and Surveillance Agency in Canada" (CIH IR 2004-2006: Timothy Caulfield, Principal Investigator: Elaine Gibson \& Bartha Maria Knoppers, CoInvestigalors). 